\title{
Microarray gene expression profiling in meningiomas: Differential expression according to grade or histopathological subtype
}

\author{
MICHELLE FÈVRE-MONTANGE ${ }^{1,5}$, JACQUES CHAMPIER $^{1,5}$, ANNE DURAND ${ }^{2}$, ANNE WIERINCKX $^{3}$, \\ JÉROME HONNORAT ${ }^{1,5}$, JACQUES GUYOTAT ${ }^{2}$ and ANNE JOUVET ${ }^{1,4,5}$ \\ ${ }^{1}$ INSERM U842, Université de Lyon, Lyon 1, UMR-S842, F-69372 Lyon; ${ }^{2}$ Service de Neurochirurgie, ${ }^{3}$ ProfilExpert, \\ ${ }^{4}$ Centre de Pathologie Est, ${ }^{5}$ Institut Fédératif des Neurosciences, Groupement Hospitalier Est 69677 Bron, France
}

Received April 6, 2009; Accepted June 4, 2009

DOI: 10.3892/ijo_00000457

\begin{abstract}
Meningiomas, one of the largest subgroup of intracranial tumours are generally benign, but can progress to malignancy. They are classified into the three World Health Organization grades: benign, atypical and anaplastic meningiomas. Various histopathological features have been associated with aggressiveness or recurrence. Several genes have been suggested as prognostic factors, but molecular signatures have not permitted the classification of the tumours into the three grades. We have performed a microarray transcriptomic study on 17 meningiomas of different malignancy using CodeLink Uniset Human Whole Genome Bioarrays to try to distinguish the different grades and histopathological subtypes. Unsupervised hierarchical clustering classified the meningiomas into groups A, B and $\mathrm{C}$, which corresponded to the three grades except for 3 benign meningiomas with higher proliferation indexes and/or recurrence, included in the atypical group. Several genes involved in cell adhesion $(C D 44, L O X)$, cell division $(C K S 2$, $B I R C 5$ and $U B E 2 C$ ), cell differentiation (Notch1) or signal transduction (ARHGAP28) were upregulated, whereas tumour suppressor genes (LR1B, DRR1, PLZF, GPX3, $S Y N P O, T I M P 3$ and $H O P S)$ and genes involved in cell adhesion (PROS1), proliferation (SERPINF1 and PDGFD) and differentiation $(A O X 1)$ were downregulated in groups $\mathrm{B}$ and $\mathrm{C}$ compared to group $\mathrm{A}$. In the benign tumours, we identified genes with signatures specific for fibroblastic meningiomas ( $F B L N 1$, Tenascin $C$ and $M M P 2$ encoding extracellular matrix proteins) and for meningothelial meningiomas (MLPH,DEFBI and FAT3), suggesting different mechanisms involved in the tumorigenesis of these
\end{abstract}

Correspondence to: Dr Michelle Fèvre-Montange, INSERM U842, Faculté de Médecine RTH Laennec, 69372 Lyon cedex 08, France

E-mail: michelle.montange@inserm.fr

Key words: meningioma, microarray, histopathological subtype, recurrence subtypes. This microarray-based expression profiling study revealed candidate genes and pathways that may contribute to a better understanding of the recurrence of a benign meningioma. Our results might make it possible to determine which benign meningiomas might recur despite complete resection, and will provide helpful information for neurosurgeons in the follow-up of the patients.

\section{Introduction}

Meningiomas constitute approximately $20 \%$ of primary intracranial tumours (1). The World Health Organization (WHO) classifies them into three grades based on histopathological criteria. Most, defined as grade I, are benign and do not recur after surgical resection, while atypical (grade II) and anaplastic (grade III) tumours have worse clinical outcomes, with frequent recurrence. However, some low-grade meningiomas also recur despite complete resection. Biological markers, such as increased expression of cathepsin-B and cathepsin-L antigens (2), S100A5 protein (3) or c-myc (4) and loss of expression of progesterone receptor (5) and tumour suppressor in lung cancer-1 (6), have been identified as predictors of recurrence in grade I meningioma. Moreover, the presence of cytogenetic aberrations in meningiomas might also be linked to increased invasive potential (7). More than $60 \%$ of meningiomas show mutation or loss of heterozygosity in the NF2 gene and these events are more frequent in fibroblastic and transitional meningiomas than in the meningothelial subtype (8). These alterations in the NF2 gene seem to be histotype-, but not grade-related $(9,10)$. Transcriptome profiles of meningiomas have been reported that showed a subset of genes differentially expressed in WHO grade I compared to WHO grades II and III (11), but, in this study, two high-grade meningiomas had expression profiles very similar to that of the non-neoplastic meninges. Another study reported differences in gene expression between WHO grades II and III, but supervised classification of the tumours did not reveal specific expression patterns for each WHO grade (12). Finally, a study using combined gene expression microarrays and array comparative genomic hybridization showed that meningiomas of all three grades fall into two main molecular groups referred to as low- and high-proliferative meningiomas (13). 
We have performed a microarray transcriptomic study on meningiomas of different malignancy grades using CodeLink Uniset Human Whole Genome Bioarrays to try to distinguish the different meningioma malignancy grades and histopathological subtypes and to more clearly define predictive factors for the recurrence of meningiomas.

\section{Material and methods}

Patients, tumours and histological diagnosis. Tumour samples from 23 patients (11 females and 12 males, mean age $54.9 \pm 2.4$ years, range 31-73) were obtained between 1998 and 2005 after surgical treatment at the Pierre Wertheimer Neurological and Neurosurgical Hospital. At surgery, the tumour tissue was divided into two fragments, one of which was frozen and stored in liquid nitrogen in the Neurobiotec Bank for RNA extraction and the other fixed for histopathological analysis. Histological examination of paraffin sections stained with hemalin-phloxin saffron was carried out at the Department of Neuropathology, Groupement Hospitalier Est, Bron. Diagnosis and classification into histological subtypes were based on WHO standard diagnostic criteria (1). In tumoral specimens fixed in $4 \%$ paraformaldehyde containing $15 \%$ picric acid or alcohol-formol-acetic acid (AFA), mitoses were counted in 10 randomly selected fields at high magnification (x400); only unequivocal mitotic figures were counted. Immunohistochemistry with anti-Ki-67 antibody (MIB1 clone, Dako, Trappes, France) was performed on 13 samples fixed in AFA to estimate cell proliferation.

RNA extraction. Total RNA, extracted from the samples using the RNA Plus procedure (Qbiogen, Illkirch, France) based on the method of Chomczinski and Sacchi (14), was precipitated with ethanol. The quality of the isolated total RNA was evaluated on nanochips using an Agilent 2100 Bioanalyzer (Agilent Technologies, Massy, France). RNA from a whole normal adult male human brain (single donor, 72 years) in $0.1 \mathrm{mM}$ EDTA, pH 8.0, was purchased from Stratagene (Stratagene Europe, Amsterdam, The Netherlands).

RNA amplification. Total RNA ( $2 \mu \mathrm{g})$ was amplified and biotin-labelled by a round of in vitro transcription using a MessageAmp aRNA kit (Ambion, Austin, TX, USA) following the manufacturer's protocol. Before amplification, spikes of different concentrations of synthetic mRNA were added to all samples and were used to determine the quality of the process. aRNA yield was measured with a UV spectrophotometer and the quality verified on nanochips using the Agilent 2100 Bioanalyzer.

Array hybridization and processing. Biotin-labelled aRNA $(10 \mu \mathrm{g})$ from 17 meningiomas were fragmented using $5 \mu \mathrm{l}$ of fragmentation buffer in a final volume of $20 \mu \mathrm{l}$, then mixed with $240 \mu 1$ of Amersham hybridization solution (GE Healthcare Europe GmbH, Saclay, France) and injected on to CodeLink Uniset Human Whole Genome Bioarrays containing 55,000 human oligonucleotide geneprobes (GE Healthcare Europe $\mathrm{GmbH}$ ). The arrays were hybridized overnight at $37^{\circ} \mathrm{C}$ at $15 \mathrm{~g}$ in an incubator, then washed in stringent TNT buffer at $46^{\circ} \mathrm{C}$ for $1 \mathrm{~h}$ before performing the streptavidin-cy 5
(GE Healthcare) detection step. Each array was incubated for $30 \mathrm{~min}$ in $3.4 \mathrm{ml}$ of streptavidin-cy5 solution as previously described (15), washed four times in $240 \mathrm{ml}$ of TNT buffer, rinsed twice in $240 \mathrm{ml}$ of water containing $0.2 \%$ Triton $\mathrm{X}$ 100 , then dried by centrifugation at $650 \mathrm{x}$ g. The arrays were scanned using a Genepix 4000B scanner (Axon, Union City, CA, USA) and Genepix software, with the laser set at 635 $\mathrm{nm}$, the laser power at $60 \%$ and the photomultiplier tube voltage at $60 \%$. The scanned image files were analysed using CodeLink expression software, version 4.0 (GE Healthcare), which produces both a raw and a normalized hybridization signal for each spot on the array.

Microarray data analysis. CodeLink software was used to normalize the raw hybridization signal on each array to the median of the array (median intensity is 1 after normalization) for better cross-array comparison. The threshold of detection was calculated using the normalized signal intensity of the 100 negative control samples in the array; spots with signal intensities below this threshold were referred to as 'absent'. The quality of processing was evaluated by generating scatter plots of positive signal distribution. Signal intensities were then converted to the log base 2 values. The expression of the genes in the normal brain was used as the standard and set to 1 .

Real-time RT-PCR. RNA samples $(0.5 \mu \mathrm{g})$ from tumours and the normal whole brain were heated for $3 \mathrm{~min}$ at $75^{\circ} \mathrm{C}$, then immediately placed on ice. First-strand DNA was synthesized by incubating the RNA with $0.5 \mathrm{mM}$ of each dNTP, $10 \mathrm{mM}$ DTT, $40 \mathrm{U}$ of RNA-sin (Promega), $20 \mu \mathrm{M}$ random hexamers, and $200 \mathrm{U}$ of Moloney murine leukaemia virus (M-MLV) reverse transcriptase (In Vitrogen, Cergy-Pontoise, France) for $90 \mathrm{~min}$ at $42^{\circ} \mathrm{C}$ in a final volume of $20 \mu \mathrm{l}$ of reverse transcriptase buffer (50 mM Tris- $\mathrm{HCl}, \mathrm{pH} 8.3,75 \mathrm{mM} \mathrm{KCl}$ and $3 \mathrm{mM} \mathrm{MgCl}$ ). The volume was then made to $100 \mu \mathrm{l}$ with distilled water. Negative controls were performed by replacing the enzyme with water.

PCR was performed on a LightCycler instrument (Roche Diagnostics, Mannheim, Germany). cDNA samples (2, 0.2 and $0.02 \mu \mathrm{l}$ ) were diluted in glass capillaries to a volume of $20 \mu 1$ with PCR mix (LightCycler Faststart DNA Master Plus SYBR-Green 1, Roche Diagnostics) containing a final concentration of $4 \mathrm{mM} \mathrm{MgCl} 2$ and $0.5 \mu \mathrm{M} 3$ '- and 5' primers. The oligonucleotide sequences corresponding to selected gene transcripts were designed using Primer 3 software (Infobiogen, Villejuif, France) and are available on request from the authors. The cDNA was denatured for $8 \mathrm{~min}$ at $95^{\circ} \mathrm{C}$, then amplified by $40-50$ cycles of $15 \mathrm{~s}$ at $95^{\circ} \mathrm{C}, 5 \mathrm{~s}$ at $62^{\circ} \mathrm{C}$ and $10 \mathrm{~s}$ at $72^{\circ} \mathrm{C}$. After amplification, the temperature was slowly raised above the melting temperature of the PCR products to measure the fluorescence for the melting curve, demonstrating the purity of the transcripts by their respective melting temperatures. Non-specific products, such as primer dimers, could be readily distinguished from the product by their lower melting point. Negative controls were also analyzed. The results were calculated from the crossing-point values and expressed as the amount of test gene product relative to the amount of GAPDH product, used as a housekeeping gene, for the same sample. To verify the presence of a single PCR product of the correct size, the product was 
Table I. Clinical and morphological data for the 23 patients.

\begin{tabular}{|c|c|c|c|c|c|c|c|c|c|c|}
\hline Case & $\begin{array}{l}\text { WHO } \\
\text { grade }\end{array}$ & $\begin{array}{l}\text { Histopathological } \\
\text { subtype }\end{array}$ & Sex & Age & Surgery & $\begin{array}{c}\mathrm{Ki}-67 \\
(\%)\end{array}$ & Mitosis & Recurrence & Microarray & $\begin{array}{l}\text { GEP } \\
\text { group }\end{array}$ \\
\hline 1 & I & Meningothelial & M & 61 & + & nd & 0 & 0 & + & A \\
\hline 2 & I & Meningothelial & $\mathrm{F}$ & 47 & + & nd & 0 & 0 & + & A \\
\hline 3 & I & Meningothelial & $\mathrm{F}$ & 50 & + & 3 & 2 & + & + & B \\
\hline 4 & I & Fibroblastic & M & 57 & + & 2 & 1 & 0 & + & A \\
\hline 5 & I & Fibroblastic & $\mathrm{F}$ & 39 & + & 1 & 0 & 0 & + & $\mathrm{A}$ \\
\hline 6 & I & Fibroblastic & $\mathrm{F}$ & 57 & + & nd & 2 & + & + & A \\
\hline 7 & I & Fibroblastic & M & 34 & + & nd & 3 & + & + & $\mathrm{B}$ \\
\hline 8 & I & Transitional & $\mathrm{F}$ & 62 & + & 1 & 1 & 0 & + & A \\
\hline 9 & I & Transitional & $\mathrm{F}$ & 67 & + & 1 & 0 & 0 & + & A \\
\hline 10 & I & Transitional & $\mathrm{F}$ & 62 & + & nd & 0 & + & + & B \\
\hline 11 & II & Atypical & M & 64 & + & nd & 0 & + & + & B \\
\hline 12 & II & Atypical & $\mathrm{F}$ & 45 & + & 8 & 1 & + & + & B \\
\hline 13 & II & Atypical & $\mathrm{F}$ & 73 & + & nd & 10 & + & + & B \\
\hline 14 & II & Atypical & M & 72 & + & 10 & 1 & + & + & B \\
\hline 15 & II & Atypical & $\mathrm{F}$ & 54 & + & 8 & 2 & 0 & + & B \\
\hline 16 & II & Atypical & M & 63 & + & nd & 10 & + & & \\
\hline 17 & III & Anaplastic & $\mathrm{F}$ & 31 & + & nd & 10 & Multi-focal & + & $\mathrm{C}$ \\
\hline 18 & III & Anaplastic & M & 52 & + & 25 & 10 & 0 & + & $\mathrm{C}$ \\
\hline 19 & III & Anaplastic & M & 55 & + & 12 & 15 & + & & \\
\hline 20 & III & Anaplastic & M & 46 & + & 20 & 22 & + & & \\
\hline 21 & III & Anaplastic & M & 70 & + & nd & $>20$ & + & & \\
\hline 22 & III & Anaplastic & M & 44 & + & 40 & $>30$ & 0 & & \\
\hline 23 & III & Anaplastic & M & 58 & + & 15 & 10 & + & & \\
\hline
\end{tabular}

nd, not done; for surgery, + represents complete exeresis; GEP, gene expression profile.

electrophoresed for $1 \mathrm{~h}$ at $70 \mathrm{~V}$ in $0.5 \mathrm{X}$ Tris-borate-EDTA buffer, pH 8.3, on a $2 \%$ agarose gel (Tebu, Le Perray-enYvelines, France), the DNA band being visualized using ethidium bromide in the presence of a DNA molecular weight standard (100 bp, Promega) under UV illumination.

Statistical analysis was performed using the Wilcoxon test.

\section{Results}

Clinical data and histological features. The clinicopathological data and histological findings for the 23 patients are shown in Table I. According to the current WHO classification, 10 tumours were grade I (3 meningothelial, 4 fibroblastic and 3 transitional), 6 grade II (atypical) and 7 grade III (anaplastic). All tumours were surgically completely resected. Thirteen recurrences were seen after surgery and one was multi-focal in a patient with grade III tumour. Of the 10 patients with WHO grade I tumours, 7 had benign tumours with a very low proliferative index $(\mathrm{Ki}-67<2 \%)$ or with no, or only one, mitosis per 10 high power field (HPF). Of these 7 , only one (case 10) had a recurrence. The other 3 of the 10 cases also had benign neoplasms, but with either a higher proliferative index $(\mathrm{Ki}-67=3)$ or more than one mitosis per $10 \mathrm{HPF}$ and all 3 showed recurrence.
Global gene expression pattern. The unsupervised hierarchical cluster of the 17 meningiomas analysed by microarray (10 grade I, 5 atypical grade II and 2 anaplastic grade III) using the level of expression of the 53429 genes classified the neoplasms into three groups, as shown in the dendrogram in Fig. 1. Group A consisted of 7 cases with grade I meningiomas, group B consisted of the 3 cases with grade I meningiomas with higher proliferation indexes and/or recurrence (cases 3, 7 and 10) plus the 5 grade II meningiomas, while group C consisted of the 2 grade III meningiomas.

Analysis of genes differentially expressed between the three meningioma groups. Of all the genes on the microarray, 346 and 2995 showed $\geq 2$-fold over-expression in group B and group C, respectively, compared to group A. The number of genes under-expressed by $\geq 2$-fold was, respectively, 184 and 1380 in group B and group C compared to group A. Comparing meningiomas in groups B and C, 1953 genes were upregulated and 508 downregulated in group B (fold change $\geq 2$ ). Only 24 genes were upregulated with a fold change of $\geq 2$ in both groups $\mathrm{B}$ and $\mathrm{C}$ compared to group $\mathrm{A}$ (listed in Table II). These included 5 genes (CD44, COL6A3, COL7A1, LAMA5 and $L O X)$ involved in cell adhesion, 5 (CKS2, CCNB1, BIRC5, PLK2 and UBEC2C) involved in cell division, one (Notchl) involved in cell proliferation/ 


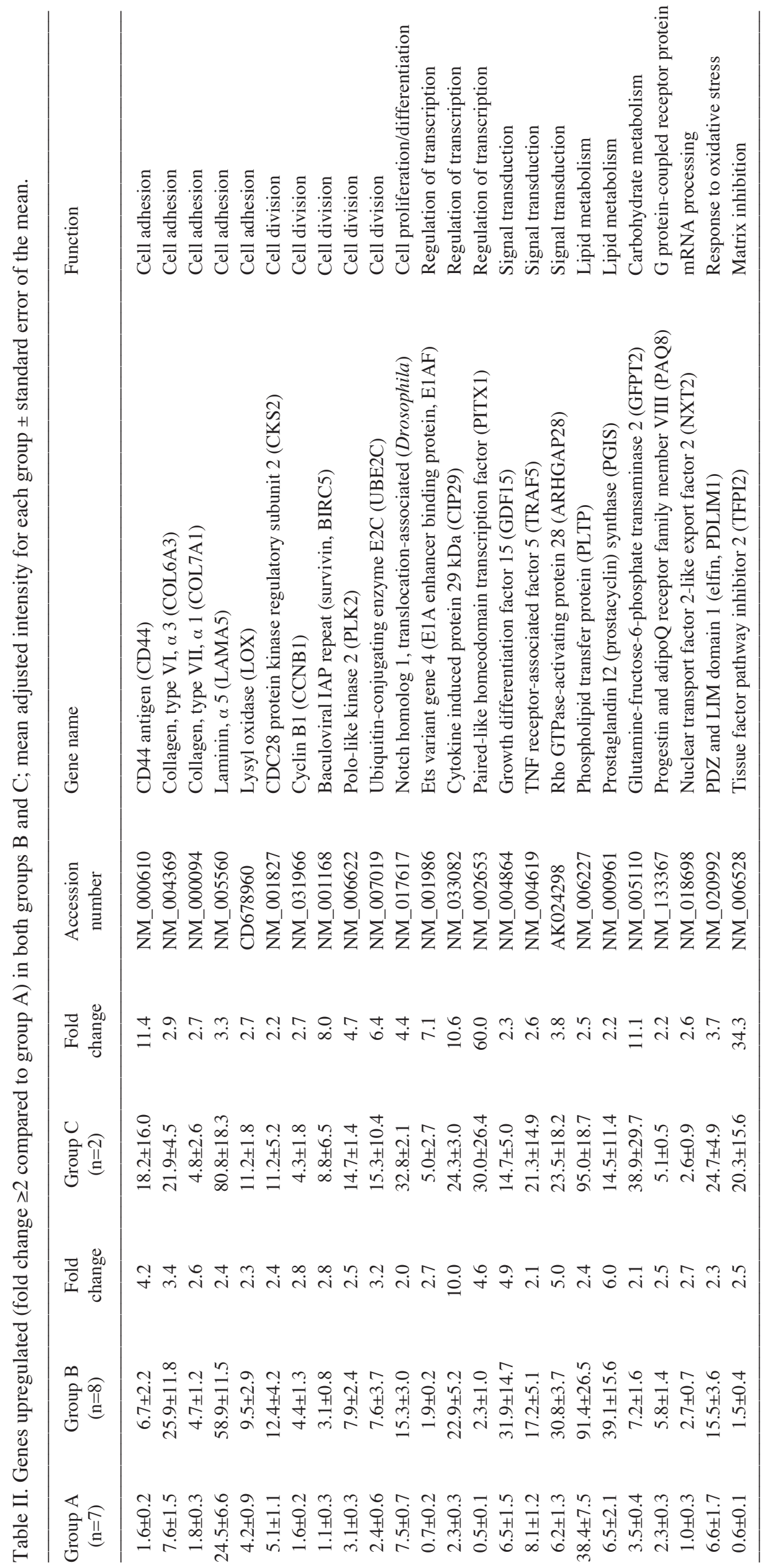




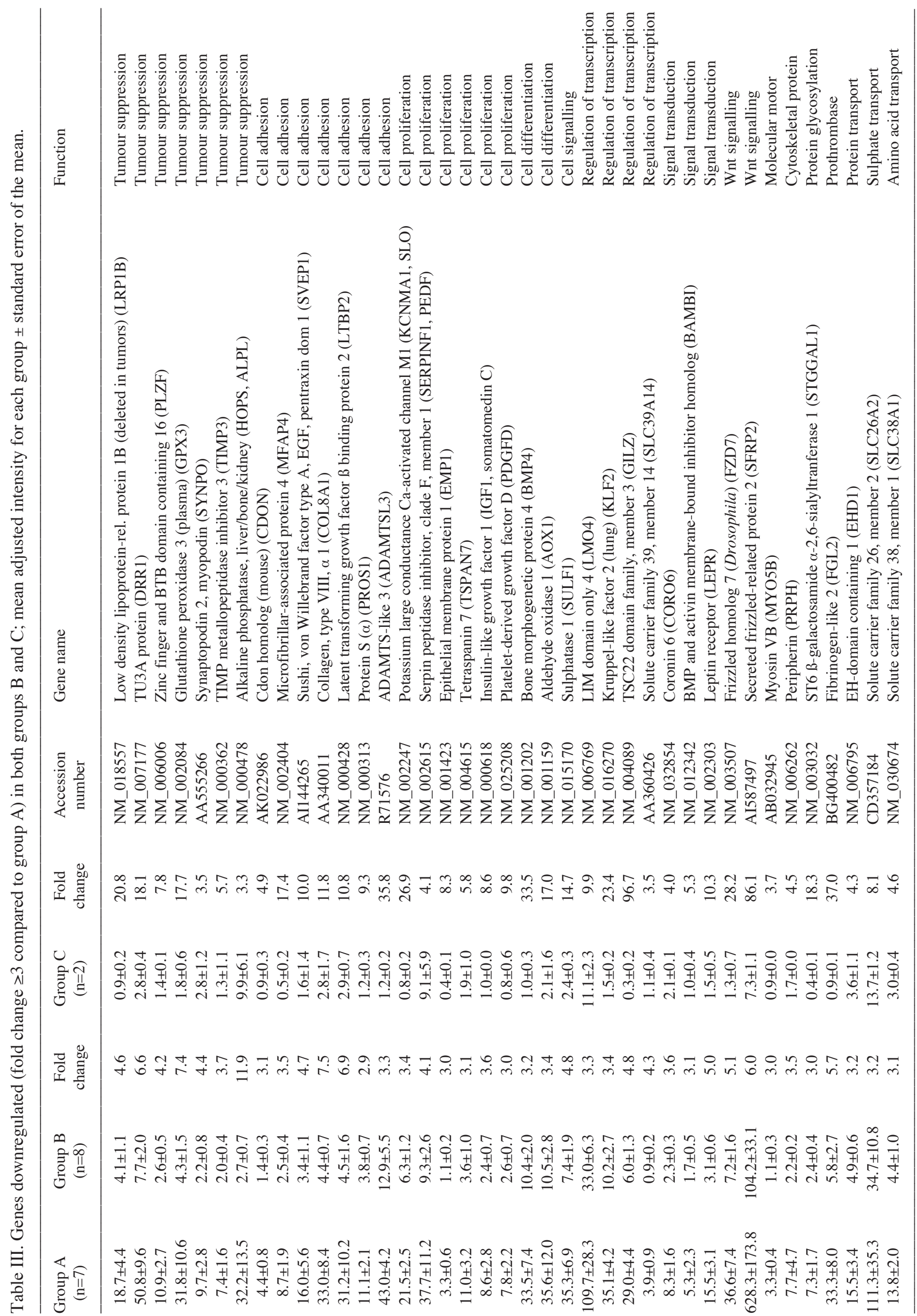




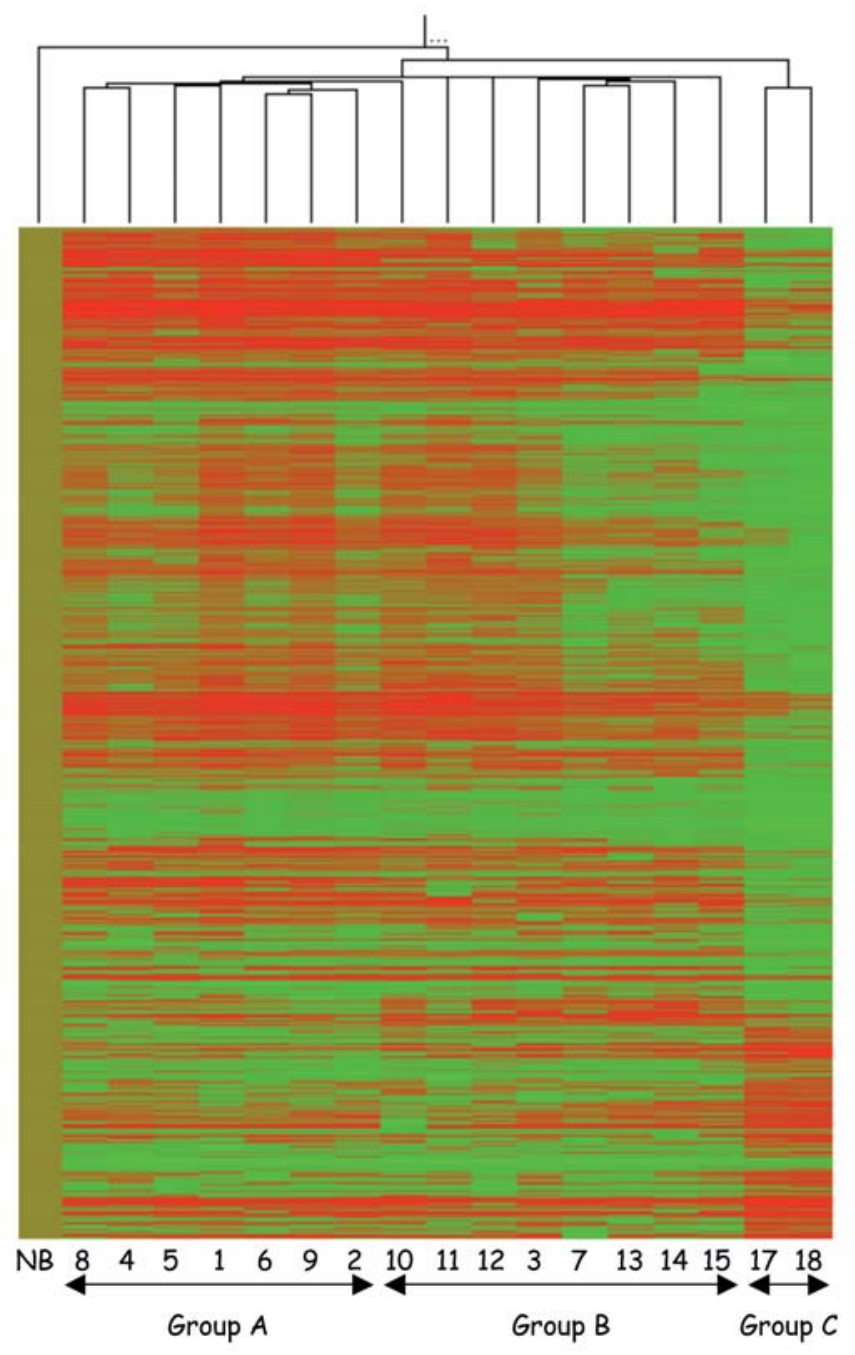

Figure 1. Gene expression profiling of meningiomas. Unsupervised hierarchical clustering of the expression data for 17 meningiomas of the three histopathological grades and from total normal brain (NB). Each column represents one case and each row represents the expression value for an individual probe.

differentiation, 3 (E1AF, CIP29 and PITX1) which regulate transcription, 3 (GDF15, TRAF5 and ARHGAP28) involved in signal transduction and 2 (PLTP and PGIS) involved in lipid metabolism. On the other hand, 226 genes were downregulated (fold change $\geq 2$ ) in both groups $\mathrm{B}$ and $\mathrm{C}$ compared to group A. Of these, only 39 showed a fold change $\geq 3$ (listed in Table III). Seven of these genes (LRPIB, DRR1, $P L Z F, G P X 3, S Y N P O, T I M P 3$ and HOPS) have been described as tumour suppressor genes, 7 (CDON, MFAP4, SVEP1, COL8A1, LTBP2, PROS1 and ADAMTSL3) are involved in cell adhesion, 6 (KCNMA1, SERPINF1, EMP1, TSPAN7, $I G F 1$ and $P D G F D$ ) have a role in cell proliferation, 2 (BMP4 and $A O X 1)$ are involved in cell differentiation, 4 (LMO4, $K L F 2, G I L Z$ and SLC39A14) are implicated in the regulation of transcription and 3 (CORO6, BAMBI and $L E P R$ ) act in signal transduction.

Of the genes which only showed differential expression in group C compared to group A, 15 are presented in Table IV. The fold change for these 15 genes ranged from 3.5 to 11.1 for the upregulated genes and from 3.4 to 42.5 for the down- regulated genes. Of the former group, 3 (JUNB, FSTL1 and Slit-2) are tumour suppressor genes.

Analysis of genes showing differential expression between fibroblastic and meningothelial meningiomas. Genes upregulated ( $>5$-fold) in one histotype compared to the other are listed in Table V. The 10 genes which showed the greatest upregulation in fibroblastic meningiomas coded for extracellular matrix proteins. In addition, $E R B B 4$, a member of the EGF receptor family, was also upregulated. In contrast, the genes upregulated in the meningothelial meningiomas encoded proteins with different functions. Three tumour suppressor genes (DEFB1, MLPH and FAT3), present only in very low amounts in fibroblastic variants, were over-expressed more than 20-fold. Several genes considered as targets of the Wnt/ß-catenin signalling pathway (EDN3, DSG2, APCDD1, $N P M 2, N F 2$ and $N E D D 4 L$ ) were upregulated, as were three genes (SSTR2, HOPS and NF2) known to be implicated in the tumorigenesis of the meningothelial subtype. Interestingly, all transitional meningiomas presented intermediate mRNA levels between fibroblastic and meningothelial tumour levels.

$q R T-P C R$ validation of differential gene expression. Of the 6 examined by qRT-PCR, 4 transcripts (HOPS, MMP9, ARHGAP28 and SPON2) examined in 22 tumours (6 lowgrade, 9 atypical and 7 anaplastic meningiomas) showed similar patterns of differential expression between group A and group $\mathrm{B}$ or $\mathrm{C}$ meningiomas to those seen on the microarray, the differences between the tumour groups being statistically significant (Fig. 2). In addition, the expression of $U B E 2 C$ and TFPI2 transcripts in the 3 groups of meningiomas showed the same pattern as that obtained by microarray, but the differences did not reach significance.

\section{Discussion}

Gene expression profiling of meningiomas belonging to the three malignancy grades allowed their classification into three molecular groups, one of low-grade meningiomas (group A), one of low-grade tumours presenting recurrence and atypical meningiomas (group B) and one of anaplastic meningiomas (group C). Some previous attempts at profiling the expression pattern of meningiomas were sometimes unable to reliably distinguish the different grades of meningiomas and to identify specific expression patterns for each grade $(11,12)$. Another showed that atypical meningiomas were not a molecularly distinct group of tumours and the authors concluded that they were similar to either benign or malignant meningiomas (13).

We focused on genes showing differential expression between these 3 groups of tumours and, more particularly, between benign meningiomas and the two other groups. We found several genes that could be potential candidates for markers for classifying the different types of meningiomas. Interestingly, the 3 patients with grade I meningiomas that were placed in group B presented a recurrence and two of the tumours showed a higher number of mitoses than usual for low-grade tumours. Previous reports have suggested a subdivision of grade I meningiomas, namely the identification of a subgroup with a higher risk of recurrence $(3,16-18)$. 

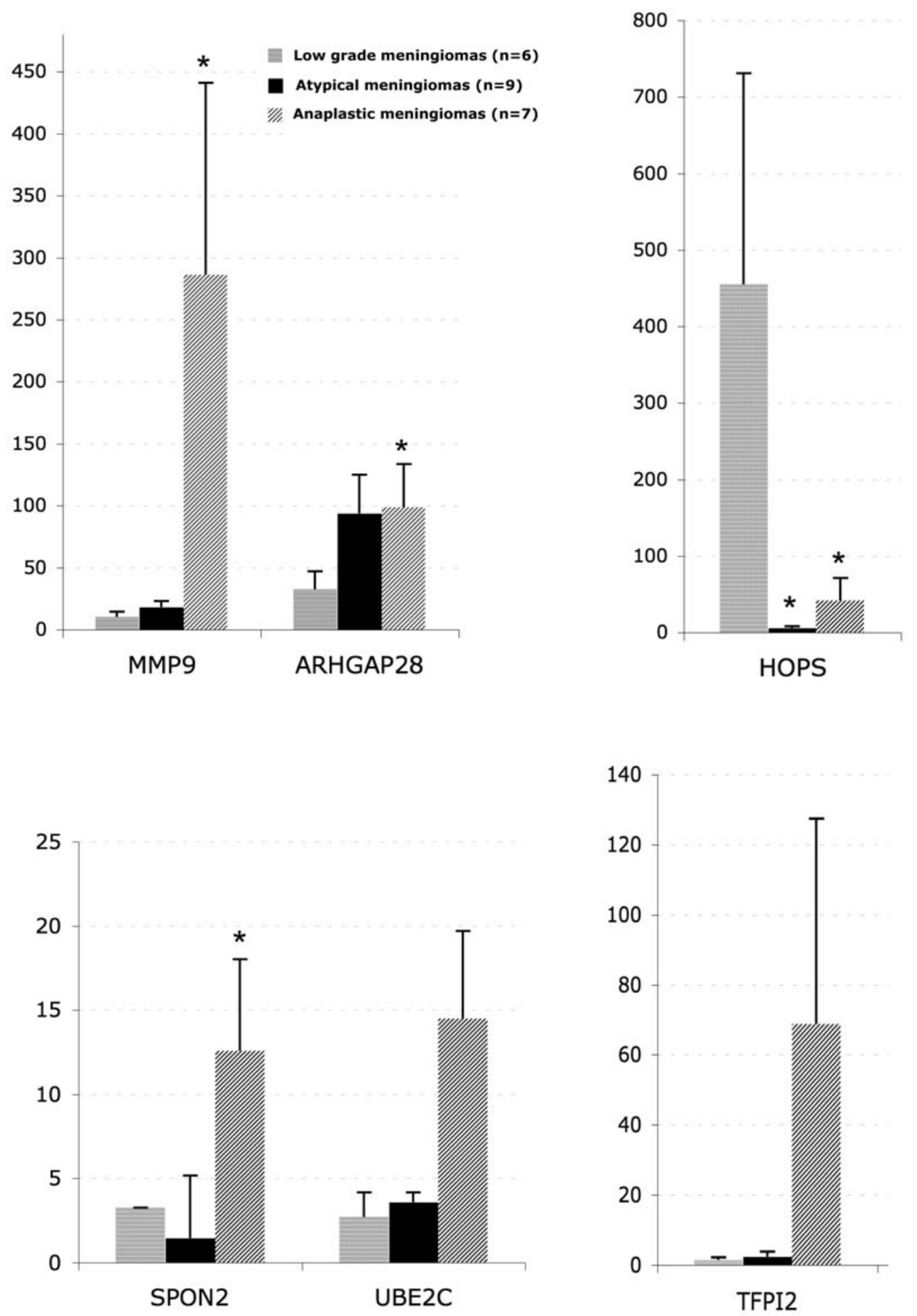

Figure 2. Transcript levels, determined by quantitative RT-PCR, of six selected genes in the three groups of meningiomas. The results are expressed as the amount of test gene product relative to the amount of GAPDH product $\left(\mathrm{x} 10^{-3}\right)$. " Statistical difference compared to low-grade meningiomas ( $<<0.05$, Wilcoxon test), means \pm standard error of the mean.

Moreover, based on c-myc expression and the clinical and histological features of the tumours, two groups of low-grade meningiomas have been defined (4). Finally, it has been shown by molecular classification that atypical meningiomas can be classed with benign meningiomas (13), suggesting that the molecular signature approach takes more into account the biological heterogeneity of meningiomas, which is not clearly defined by histopathological criteria.
We identified several genes that may represent progressionassociated markers. Among the genes upregulated in nonbenign meningiomas or in those benign meningiomas presenting recurrence, 3 (CKS2, UBE2C and TFPI2) were already known to be overexpressed in grade II or grade III meningiomas (13). Numerous reports have demonstrated that $C K S 2$ expression is frequently elevated in tumours of different tissue origins, including metastatic colon cancer (19), high- 


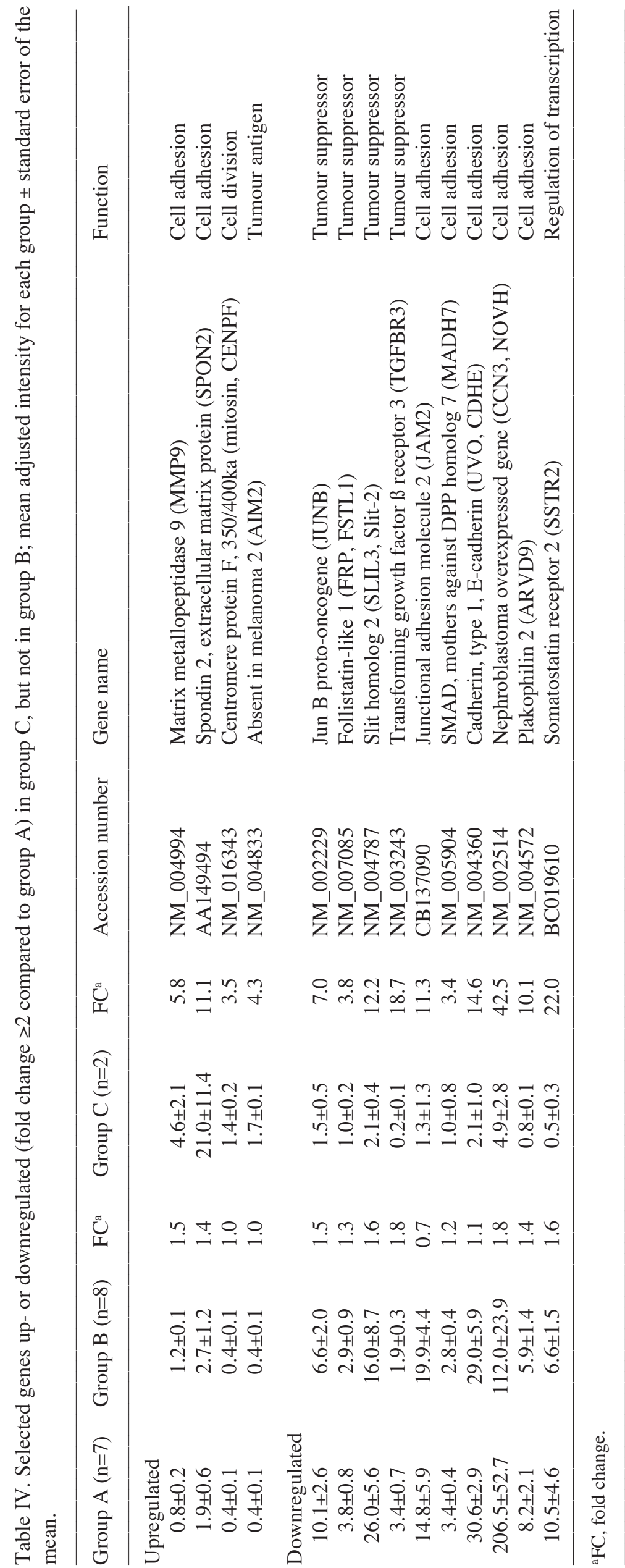




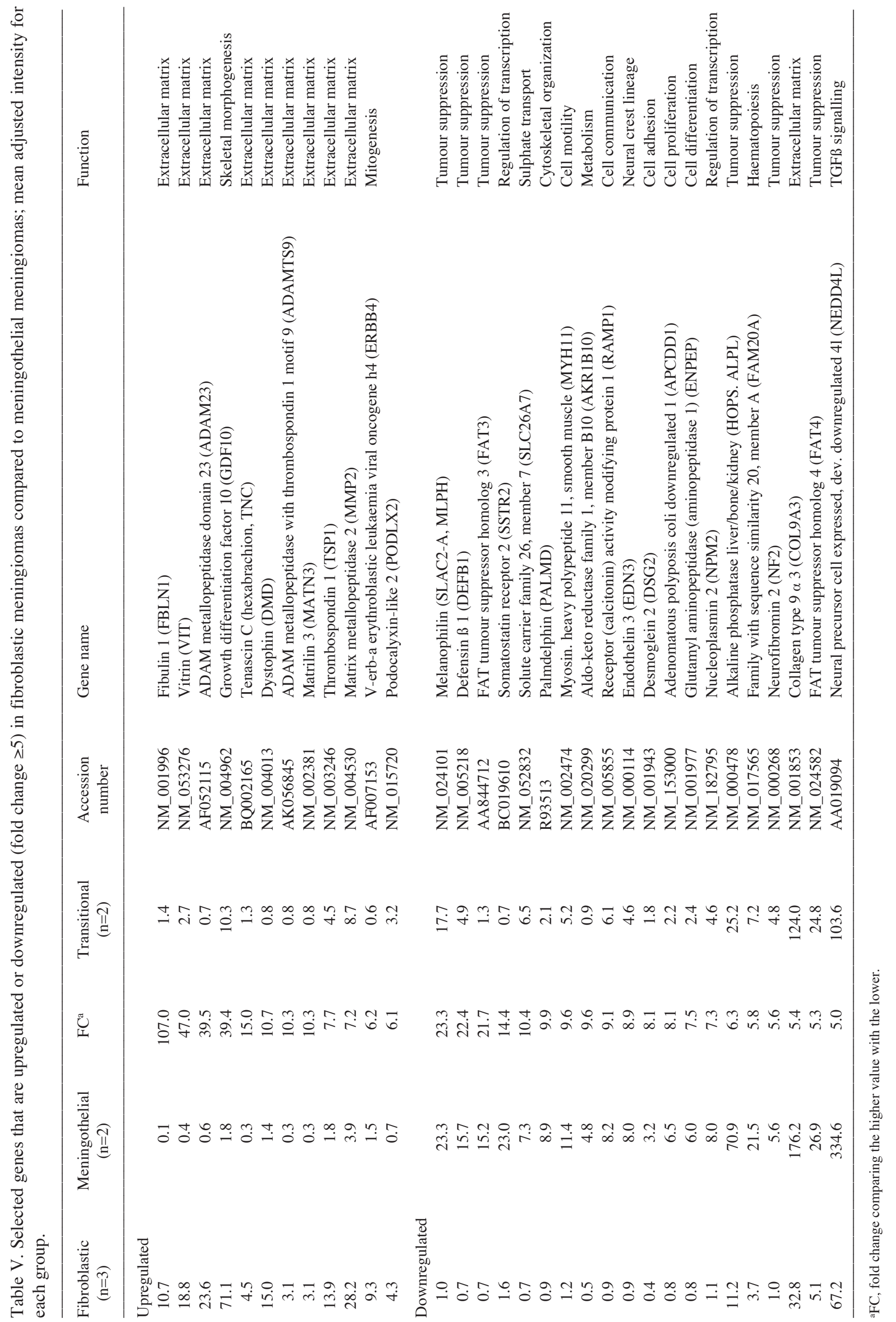


grade gliomas $(20,21)$ and prostate cancer (22); in these prostate tumour cells, aberrant $C K S 2$ expression may promote tumorigenicity by protecting the cells from apoptosis (22). $U B E 2 C$ expression has frequently been correlated with tumour grade. This gene has been shown to be overexpressed in malignant breast carcinomas (23), in hepatocellular carcinoma, in which it is associated with tumour progression (24), in anaplastic thyroid carcinomas, in which it plays a role in thyroid cell proliferation (25), and in high-grade glial tumours (26). Since proteasome inhibitors have been considered as possible drugs for the chemotherapy of various tumours, new perspectives for the treatment of high-grade meningiomas based on the suppression of UBE2C function might be proposed. Moreover, several of the overexpressed genes play a role in cell adhesion. Strong CD44 expression has been demonstrated in atypical meningioma cells (27), but no correlation between CD44 immunolabelling and tumour grade was observed in another report on meningiomas (28). Upregulation of CD44 in cultures of meningiomas has been demonstrated by microarray (29). The expression of this hyaluronate receptor transcript may support a role of this molecule in the invasive growth potential of neoplastic cells. In addition, the role of LOX as a promoter of metastasis has been well documented in different types of tumours (30) but upregulation of its transcript according to the grade of meningioma has not been previously reported.

Transcript levels of 39 genes were downregulated in both group $\mathrm{B}$ and $\mathrm{C}$ meningiomas, possibly corresponding to a loss of differentiation of neoplasms in these 2 groups. Of these, 7 have already been described as tumour suppression genes showing decreased expression in high-grade neoplasms. Expression of $L R P 1 B$, which belongs to the low density lipoprotein receptor gene family, is inactivated by genetic and transcript alterations in non-small cell lung cancer (31) or altered by deletion in high-grade urothelial cancer (32) and the region of the chromosome containing the gene is frequently deleted in squamous cell cervical carcinoma (33). Loss of $D D R 1$, originally named $T U 3 A$, is also frequently seen in other high-grade tumours, such as renal cell carcinoma (34), and downregulation of its expression may also contribute to glioma progression (35). PLZF mRNA expression has been shown to be downregulated during melanoma progression (36). Decreased expression of GPX3, SYNPO and TIMP3 has been previously reported in meningiomas (13). Moreover, $G P X 3$ is one of the genes most often downregulated or deleted in prostate cancer and this decreased expression may be associated with the aggressive behaviour of these tumours (37). The frequent loss of expression of TIMP3 (a tissue inhibitor of matrix metalloproteinase involved in regulation of cell proliferation) as a result of genetic loss or methylation of the gene has been associated with progression of oesophageal and gastric adenocarcinomas (38). In these neoplasms, immunohistochemical analysis showed that loss of TIMP3 expression is especially frequent in tumours with poor differentiation (38). In meningiomas, no hypermethylation of the TIMP3 promoter has been detected (39) and no aberrant gene methylation of this gene has been reported (40). The silencing of the TIMP3 gene or its deletion, as it is located in a genomic region, $22 \mathrm{q} 12$, that is frequently deleted in meningioma (41), might be involved in the progression of this neoplasm. Interestingly, our results demonstrated a dramatic downregulation of alkaline phosphatase (HOPS) mRNA expression in atypical and anaplastic meningiomas, by microarray and, in a larger number of patients by RT$\mathrm{PCR}$. This is in agreement with histoenzymological reports showing reduced levels of HOPS enzyme in high-grade meningiomas $(42,43)$. Moreover, reduced HOPS protein expression had been reported in a grade I meningioma in one patient who presented recurrence after surgery (42). In our study, the 3 grade I meningiomas which were included by molecular clustering in the group of atypical meningiomas also showed reduced HOPS transcript expression. The physiologic role of this enzyme is still poorly understood, but its detection might help in assessing risk of recurrence, especially in those borderline atypical meningiomas in which not all criteria are present for their classification as grade II. Moreover, the high expression of HOPS in meningothelial compared to fibroblastic meningiomas has not been previously described. Several other genes (SVEP1, COL8A1, LTBP2, SLO, SERPINF 1, PDGFD, BMP4, LMO4, SFRP2 and $S L C 26 A 2)$, found to be downregulated in high-grade meningiomas in this study, have been previously reported with reduced expression in high-grade meningiomas (13). The inhibition of expression of some of these genes has been shown to be involved in tumorigenesis; this has been demonstrated for SLO in osteosarcoma (44), for SERPINF 1 in breast cancer (45) and non-small cell lung cancer (46) and for LMO4 in several tumour types, including breast, prostate and pancreatic ductal adenocarcinomas (47). Furthermore, the frequent presence of ADAMTSL3 mutations has been reported in colorectal cancer (48) and decreased ADAMTSL3 mRNA expression, as observed in colorectal malignancy (48), may contribute to the progression of meningiomas. Finally, complete loss or reduced expression of AOX1, a xenobiotic metabolizing enzyme, has been reported in hepatocellular carcinomas, with a significant correlation between AOX1 expression and tumour stage (49).

Among the genes only overexpressed in group $\mathrm{C}$ meningiomas compared to group A, CENPF, which encodes mitosin, a protein involved in cell cycle progression, can be considered as a marker of early recurrence in intracranial meningiomas (50) and as a prognostic factor for the recurrence of meningiomas (51). This molecule has also been described as a biomarker associated with poor outcome in breast cancer (52). MMP9, a component of the extracellular matrix, has been shown to be upregulated in atypical and anaplastic meningiomas $(18,53)$ and has been proposed as a potential target for therapy in meningiomas (54). In contrast, the expression of SPON2, which has been shown to be overexpressed in ovarian cancer (55), and the expression of AIM2 have not been previously reported in meningiomas. Among the genes only downregulated in group $C$ meningiomas compared to group A, 4 (JUNB, FSTL1, TGFBR3 and $M A D H 7)$ involved in the transforming growth factor- $\beta$ signalling pathway have been previously shown to be downregulated in malignant meningiomas (13). The decreased expression of the protooncogene JUNB, a cell proliferation inhibitor and a repressor of MMP9, might explain the upregulation of MMP9 observed in high-grade meningiomas (56). Furthermore, Slit-2 has been described as a tumour 
suppressor gene because it is frequently inactivated in various cancers due to hypermethylation of its promoter region (57). Its expression has been reported to be decreased or abolished in human oesophageal squamous cell carcinomas compared to normal tissues, as shown by in situ hybridization (58). Conflicting results on the relationship between E-cadherin expression and tumour grade have been reported in meningiomas (59). Our data show that loss of expression of Ecadherin in meningiomas seems to be associated with increased malignancy, as previously described in an immunohistochemical study (60).

Molecular signatures specific for different histopathological types of meningiomas, more particularly fibroblastic and meningothelial variants, have not previously been clearly identified by microarray studies. Only one recent study using unsupervised RNA cluster analysis of 27 meningiomas clustered the fibroblastic meningiomas separately from the other meningiomas and identified several genes, including $B M P R 1 B, D M D$ and $R A M P 1$, with expression signatures specific for fibroblastic meningiomas (61). Our results confirm that several genes are differentially expressed in fibroblastic and meningothelial meningiomas. The presence of a collagenrich matrix in fibroblastic meningiomas may be due to the upregulation of several genes with an extracellular matrix function in this type of tumour. As many of these proteins, such as tenascin (62), are expressed in the foetal meninges, their re-expression in fibroblastic meningiomas may be involved in the proliferation and adhesion of tumoral cells. Fibulin-1, known to be required for the directed migration and survival of cranial neural crest cells (63), is present at high levels in the matrix of the leptomeningeal anlage (64), and can suppress the motility of many types of cancer cells (65). Meningothelial meningiomas overexpress several genes known to be tumour suppressor genes, such as $\beta$ - defensin-1, which can inhibit cancer cell proliferation in renal cell carcinoma (66). Other genes overexpressed in meningothelial meningiomas, such as FAT3 and FAT4, encode proteins involved in cell-cell junction formation (67). FAT4 has also been shown to be a tumour suppressor gene in breast cancer (68). Similarly, the expression of neurofibromatosis 2 (NF2), a tumour suppressor gene, was found to be increased in meningothelial meningiomas, in agreement with previous results $(4,10)$. Merlin, the protein encoded by NF2, regulates cadherin-mediated cell contacts (69). Finally, higher expression of $s s t 2$ was also observed in meningothelial meningiomas, as reported previously (4).

Microarray transcriptomic studies might be a useful complement to conventional diagnosis (70). Our data on the differential expression of gene transcripts in the three groups of meningiomas remain to be validated immunohistochemically when antibodies are available for proteins such as CKS2, UBE2C, GPX3, AOX1 and SERPINF1. We are currently examining the correlation between gene expression and patient survival in a large number of meningiomas.

\section{Acknowledgements}

We are greatly indebted to Neurobiotec and to the neurosurgeons at the Groupement Hospitalier Est Bron, for supplying the tumour samples. We also thank T. Barkas for linguistic help. This work was supported by INSERM, the Ligue Nationale contre le Cancer (Loire) and the Région RhôneAlpes.

\section{References}

1. Perry A, Louis DN, Scheithauer BW, Budka H and Von Deimling A: Meningioma. In: WHO Classification of Tumours of the Central Nervous System. 4th edition. Louis DN, Ohgaki H, Wiestler OD, Cavenee WK (eds). International Agency for Research on Cancer, Lyon, pp164-172, 2007.

2. Strojnik T, Zidanik B, Kos J and Lah TT: Cathepsins B and L are markers for clinically invasive types of meningiomas. Neurosurgery 48: 598-605, 2001.

3. Hancq S, Salmon I, Brotchi J, et al: S100A5: a marker of recurrence in WHO grade I meningiomas. Neuropathol Appl Neurobiol 30: 178-187, 2004.

4. Durand A, Champier J, Jouvet A, Labrousse F, Honnorat J, Guyotat J and Fevre-Montange M: Expression of c-Myc, neurofibromatosis Type 2, somatostatin receptor 2 and erb-B2 in human meningiomas: relation to grades or histotypes. Clin Neuropathol 27: 334-345, 2008.

5. Konstantinidou AE, Korkolopoulou P, Mahera H, Kotsiakis X, Hranioti S, Eftychiadis C and Patsouris E: Hormone receptors in non-malignant meningiomas correlate with apoptosis, cell proliferation and recurrence-free survival. Histopathology 43: 280-290, 2003.

6. Surace EI, Lusis E, Murakami Y, Scheithauer BW, Perry A and Gutmann DH: Loss of tumor suppressor in lung cancer-1 (TSLC1) expression in meningioma correlates with increased malignancy grade and reduced patient survival. J Neuropathol Exp Neurol 63: 1015-1027, 2004.

7. Perry A, Giannini C, Raghavan R, et al: Aggressive phenotypic and genotypic features in pediatric and NF2-associated meningiomas: a clinicopathologic study of 53 cases. J Neuropathol Exp Neurol 60: 994-1003, 2001.

8. Lamszus K: Meningioma pathology, genetics, and biology: J Neuropathol Exp Neurol 63: 275-286, 2004.

9. Ragel BT and Jensen RL: Molecular genetics of meningiomas. Neurosurg Focus 19: E9, 2005.

10. Wellenreuther R, Kraus JA, Lenartz D, et al: Analysis of the neurofibromatosis 2 gene reveals molecular variants of meningioma. Am J Pathol 146: 827-832, 1995.

11. Watson MA, Gutmann DH, Peterson K, Chicoine MR, Kleinschmidt-DeMasters BK, Brown HG and Perry A: Molecular characterization of human meningiomas by gene expression profiling using high-density oligonucleotide microarrays. Am J Pathol 161: 665-672, 2002.

12. Wrobel G, Roerig P, Kokocinski F, Neben K, Hahn M, Reifenberger G and Lichter P: Microarray-based gene expression profiling of benign, atypical and anaplastic meningiomas identifies novel genes associated with meningioma progression. Int J Cancer 114: 249-256, 2005.

13. Carvalho LH, Smirnov I, Baia GS, et al: Molecular signatures define two main classes of meningiomas. Mol Cancer 6: 64, 2007.

14. Chomczynski P and Sacchi N: The single-step method of RNA isolation by acid guanidinium thiocyanate-phenol-chloroform extraction: twenty-something years on. Nat Protoc 1: 581-585, 2006.

15. Fevre-Montange M, Champier J, Szathmari A, et al: Microarray analysis reveals differential gene expression patterns in tumors of the pineal region. J Neuropathol Exp Neurol 65: 675-684, 2006.

16. Lusis E and Gutmann DH: Meningioma: an update. Curr Opin Neurol 17: 687-692, 2004.

17. Maes L, Kalala JP, Cornelissen M and De Ridder L: PCNA, $\mathrm{Ki}-67$ and hTERT in residual benign meningiomas. In Vivo 20: 271-275, 2006.

18. Okuducu AF, Zils U, Michaelis SA, Mawrin C and von Deimling A Increased expression of avian erythroblastosis virus E26 oncogene homolog 1 in World Health Organization grade 1 meningiomas is associated with an elevated risk of recurrence and is correlated with the expression of its target genes matrix metalloproteinase-2 and MMP-9. Cancer 107: 1365-1372, 2006.

19. Li M, Lin YM, Hasegawa S, Shimokawa T, et al: Genes associated with liver metastasis of colon cancer, identified by genome-wide cDNA microarray. Int J Oncol 24: 305-312, 2004. 
20. Rickman DS, Bobek MP, Misek DE, et al: Distinctive molecular profiles of high-grade and low-grade gliomas based on oligonucleotide microarray analysis. Cancer Res 61: 6885-6891, 2001.

21. Scrideli CA, Carlotti CG Jr, Okamoto OK, et al: Gene expression profile analysis of primary glioblastomas and nonneoplastic brain tissue: identification of potential target genes by oligonucleotide microarray and real-time quantitative PCR. J Neurooncol 88: 281-291, 2008.

22. Lan Y, Zhang Y, Wang J, Lin C, Ittmann MM and Wang F: Aberrant expression of $\mathrm{Cks} 1$ and $\mathrm{Cks} 2$ contributes to prostate tumorigenesis by promoting proliferation and inhibiting programmed cell death. Int J Cancer 123: 543-551, 2008.

23. Berlingieri MT, Pallante P, Sboner A, et al: UbcH10 is overexpressed in malignant breast carcinomas. Eur J Cancer 43: 2729-2735, 2007

24. Ieta K, Ojima E, Tanaka F, et al: Identification of overexpressed genes in hepatocellular carcinoma, with special reference to ubiquitin-conjugating enzyme E2C gene expression. Int J Cancer 121: 33-38, 2007.

25. Pallante P, Berlingieri MT, Troncone G, et al: UbcH10 overexpression may represent a marker of anaplastic thyroid carcinomas. Br J Cancer 93: 464-471, 2005.

26. Jiang L, Huang CG, Lu YC, et al: Expression of ubiquitinconjugating enzyme $\mathrm{E} 2 \mathrm{C} / \mathrm{UbcH} 10$ in astrocytic tumors. Brain Res 1201: 161-166, 2008

27. Lewy-Trenda I, Omulecka A, Janczukowicz J and Papierz W: CD44 expression in human meningiomas: an immunohistochemical analysis. Pol J Pathol 55: 33-37, 2004.

28. Panagopoulos AT, Lancellotti CL, Veiga JC, De Aguiar PH and Colquhoun A: Expression of cell adhesion proteins and proteins related to angiogenesis and fatty acid metabolism in benign, atypical, and anaplastic meningiomas. J Neurooncol 89: 73-87, 2008.

29. Sasaki T, Hankins GR and Helm GA: Comparison of gene expression profiles between frozen original meningiomas and primary cultures of the meningiomas by GeneChip. Neurosurgery 52: 892-898, 2003

30. Payne SL, Hendrix MJ and Kirschmann DA: Paradoxical roles for lysyl oxidases in cancer - a prospect. J Cell Biochem 101: 1338-1354, 2007

31. Liu CX, Musco S, Lisitsina NM, Yaklichkin SY and Lisitsyn NA: Genomic organization of a new candidate tumor suppressor gene, LRP1B. Genomics 69: 271-274, 2000.

32. Langbein S, Szakacs O, Wilhelm M, et al: Alteration of the LRP1B gene region is associated with high grade of urothelial cancer. Lab Invest 82: 639-643, 2002.

33. Choi YW, Bae SM, Kim YW, et al: Gene expression profiles in squamous cell cervical carcinoma using array-based comparative genomic hybridization analysis. Int J Gynecol Cancer 17: 687-696, 2007.

34. Yamato T, Orikasa K, Fukushige S, Orikasa S and Horii A: Isolation and characterization of the novel gene, TU3A, in commonly deleted region on $3 \mathrm{p} 14.3 \rightarrow \mathrm{p} 14.2$ in renal cell carcinoma. Cytogenet Cell Genet 87: 291-295, 1999.

35. Van den Boom J, Wolter M, Blaschke B, Knobbe CB and Reifenberger G: Identification of novel genes associated with astrocytoma progression using suppression subtractive hybridization and real-time reverse transcription-polymerase chain reaction. Int J Cancer 119: 2330-2338, 2006.

36. Brunner G, Reitz M, Schwipper V, et al: Increased expression of the tumor suppressor PLZF is a continuous predictor of longterm survival in malignant melanoma patients. Cancer Biother Radiopharm 23: 451-459, 2008

37. Yu YP, Yu G, Tseng G, Cieply K, et al: Glutathione peroxidase 3 , deleted or methylated in prostate cancer, suppresses prostate cancer growth and metastasis. Cancer Res 67: 8043-8050, 2007.

38. Gu P, Xing X, Tanzer M, Rocken C, et al: Frequent loss of TIMP-3 expression in progression of esophageal and gastric adenocarcinomas. Neoplasia 10: 563-572, 2008.

39. Liu Y, Pang JC, Dong S, Mao B, Poon WS and Ng HK: Aberrant $\mathrm{CpG}$ island hypermethylation profile is associated with atypical and anaplastic meningiomas. Hum Pathol 36: 416-425, 2005.

40. Bello MJ, Aminoso C, Lopez-Marin I, et al: DNA methylation of multiple promoter-associated $\mathrm{CpG}$ islands in meningiomas: relationship with the allelic status at $1 p$ and 22q. Acta Neuropathol 108: 413-421, 2004.

41. Ng HK, Lau KM, Tse JY, Lo KW, Wong JH, Poon WS and Huang DP: Combined molecular genetic studies of chromosome $22 \mathrm{q}$ and the neurofibromatosis type 2 gene in central nervous system tumors. Neurosurgery 37: 764-773, 1995.
42. Bouvier C, Liprandi A, Colin C, Giorgi R, Quilichini B, Metellus $\mathrm{P}$ and Figarella-Branger D: Lack of alkaline phosphatase activity predicts meningioma recurrence. Am J Clin Pathol 124: 252-258, 2005

43. Kim YJ, Ketter R, Henn W, Zang KD, Steudel WI and Feiden W: Histopathologic indicators of recurrence in meningiomas: correlation with clinical and genetic parameters. Virchows Arch 449: 529-538, 2006.

44. Cambien B, Rezzonico R, Vitale S, et al: Silencing of hSlo potassium channels in human osteosarcoma cells promotes tumorigenesis. Int J Cancer 123: 365-371, 2008.

45. Cai J, Parr C, Watkins G, Jiang WG and Boulton M: Decreased pigment epithelium-derived factor expression in human breast cancer progression. Clin Cancer Res 12: 3510-3517, 2006.

46. Zhang L, Chen J, Ke Y, Mansel RE and Jiang WG: Expression of pigment epithelial derived factor is reduced in non-small cell lung cancer and is linked to clinical outcome. Int J Mol Med 17: 937-944, 2006.

47. Murphy NC, Scarlett CJ, Kench JG, et al: Expression of LMO4 and outcome in pancreatic ductal adenocarcinoma. Br J Cancer 98: 537-541, 2008

48. Koo BH, Hurskainen T, Mielke K, Aung PP, Casey G, AutioHarmainen $\mathrm{H}$ and Apte SS: ADAMTSL3/punctin-2, a gene frequently mutated in colorectal tumors, is widely expressed in normal and malignant epithelial cells, vascular endothelial cells and other cell types, and its mRNA is reduced in colon cancer. Int J Cancer 121: 1710-1716, 2007.

49. Sigruener A, Buechler C, Orso E, et al: Human aldehyde oxidase 1 interacts with ATP-binding cassette transporter-1 and modulates its activity in hepatocytes. Horm Metab Res 39: 781-789, 2007.

50. Konstantinidou AE, Korkolopoulou P, Kavantzas N, et al: Mitosin, a novel marker of cell proliferation and early recurrence in intracranial meningiomas. Histol Histopathol 18: 67-74, 2003.

51. Okada M, Miyake K, Matsumoto Y, Kawai N, Kunishio K and Nagao S: Matrix metalloproteinase-2 and matrix metalloproteinase-9 expressions correlate with the recurrence of intracranial meningiomas. J Neurooncol 66: 29-37, 2004.

52. O'Brien SL, Fagan A, Fox EJ, et al: CENP-F expression is associated with poor prognosis and chromosomal instability in patients with primary breast cancer. Int J Cancer 120: 1434-1443, 2007.

53. Martinez-Glez V, Franco-Hernandez C, Alvarez L, et al: Meningiomas and schwannomas: molecular subgroup classification found by expression arrays. Int J Oncol 34: 493-504, 2009.

54. Das A, Tan WL and Smith DR: Expression of extracellular matrix markers in benign meningiomas. Neuropathology 23: 275-281, 2003.

55. Simon I, Liu Y, Krall KL, Urban N, Wolfert RL, Kim NW and McIntosh MW: Evaluation of the novel serum markers B7-H4, Spondin 2, and DcR3 for diagnosis and early detection of ovarian cancer. Gynecol Oncol 106: 112-118, 2007.

56. Rylski M, Amborska R, Zybura K, et al: JunB is a repressor of MMP-9 transcription in depolarized rat brain neurons. Mol Cell Neurosci 40: 98-110, 2009.

57. Prasad A, Paruchuri V, Preet A, Latif F and Ganju RK: Slit-2 induces a tumor-suppressive effect by regulating beta-catenin in breast cancer cells. J Biol Chem 283: 26624-26633, 2008.

58. Kim HK, Zhang H, Li H, et al: Slit2 inhibits growth and metastasis of fibrosarcoma and squamous cell carcinoma. Neoplasia 10: 1411-1420, 2008

59. Brunner EC, Romeike BF, Jung M, Comtesse N and Meese E: Altered expression of beta-catenin/E-cadherin in meningiomas. Histopathology 49: 178-187, 2006.

60. Schwechheimer K, Zhou L and Birchemeier W: E-Cadherin in human brain tumours: loss of immunoreactivity in malignant meningiomas. Virchows Arch 432: 163-167, 1998.

61. Aarhus M, Bruland O, Bredholt G, et al: Microarray analysis reveals down-regulation of the tumour suppressor gene WWOX and up-regulation of the oncogene TYMS in intracranial sporadic meningiomas. J Neurooncol 88: 251-259, 2008.

62. Montagnani S, Castaldo C, Di Meglio F, Sciorio S and Giordano-Lanza G: Extracellular matrix features in human meninges. Ital J Anat Embryol 105: 167-177, 2000.

63. Cooley MA, Kern CB, Fresco VM, et al: Fibulin-1 is required for morphogenesis of neural crest-derived structures. Dev Biol 319: 336-345, 2008

64. Miosge N, Gotz W, Sasaki T, Chu ML, Timpl R and Herken R: The extracellular matrix proteins fibulin-1 and fibulin-2 in the early human embryo. Histochem J 28: 109-116, 1996. 
65. Twal WO, Czirok A, Hegedus B, et al: Fibulin-1 suppression of fibronectin-regulated cell adhesion and motility. J Cell Sci 114: 4587-4598, 2001.

66. Sun CQ, Arnold R, Fernandez-Golarz C, et al: Human betadefensin-1, a potential chromosome $8 \mathrm{p}$ tumor suppressor: control of transcription and induction of apoptosis in renal cell carcinoma. Cancer Res 66: 8542-8549, 2006.

67. Nagae S, Tanoue $\mathrm{T}$ and Takeichi M: Temporal and spatial expression profiles of the Fat 3 protein, a giant cadherin molecule, during mouse development. Dev Dyn 236: 534-543, 2007
68. Qi C, Zhu YT, Hu L and Zhu YJ: Identification of Fat4 as a candidate tumor suppressor gene in breast cancers. Int J Cancer 124: 793-798, 2009.

69. Lallemand D, Curto M, Saotome I, Giovannini M and McClatchey AI: NF2 deficiency promotes tumorigenesis and metastasis by destabilizing adherens junctions. Genes Dev 17: 1090-1100, 2003.

70. Martinez-Gles V, Franco-Hernandez C and Rey JA: Microarray gene expression profiling in meningiomas and schwannomas. Curr Med Chem 15: 826-833, 2008. 